\title{
Lifestyle Intervention Reduces TPO Antibody Level in Euthyroid Patients: A Retrospective Cohort Study
}

Authors : Chen liang , Kuang jian, Pei jianhao, Chen hongmei, Chen zhong, Li zhongwen, Yang huazhang , Fu xiaoyin ,Wang long , Chen zhijiang , Linjinxin

Hospital: The First Division of Endocrinology, Guangdong General Hospital, Guangdong Academy of Medical Sciences, 106th of Zhongshan Er Road, Guangzhou 510080, China.

\section{OBJECTIVES}

To investigate the impact of lifestyle intervention on elevated serum thyroid peroxidase antibody (TPO) levels in outpatients with normal thyroid function.

\section{METHODS}

A retrospective cohort study was performed to observe and evaluate euthyroid patients with excessive TPO antibodies that presented to the authors' hospital between March 2013 and October 2014 for routine medical examinations. The subjects were randomly divided into the lifestyle intervention group and the control group. Lifestyle interventions, including diet improvement and adequate sleep, were instituted immediately following the medical examination for 12-24 weeks. Both groups had patients taking either selenium supplements or Chinese herbal medicines. The difference between the two groups in TPO antibody level was compared after lifestyle intervention.

\section{RESULTS}

The TPO antibody level decreased by $30 \%$ in the intervention group and only $5 \%$ in the control group $(P<.05)$.

\section{CONCLUSIONS}

Increased TPO antibody level is often related to autoimmune thyroid disorders and inflammation, including conditions such as toxic goiter or autoimmune thyroiditis. The present cohort study demonstrated that lifestyle intervention can effectively improve early-stage thyroid disorders.

\section{References}

1. Lanas A, Letelier C, Caamaño E, Massardo T, González P, Araya AV. [Frequency of positive anti thyroid peroxidase antibody titers among normal individuals]. Rev Med Chil. 2010 Jan;138(1):15-21. doi: /S0034-98872010000100002. Epub 2010 Mar 26. Spanish.

2.Prummel MF, Wiersinga WM. Thyroid peroxidase autoantibodies in euthyroid subjects. Best Pract Res Clin Endocrinol Metab. 2005 Mar; 19(1):1-15. Review.

3. Balázs C. [The role of hereditary and environmental factors in autoimmune thyroid diseases]. Orv Hetil. 2012 Jul 1;153(26):101322. doi: 10.1556/OH.2012.29370. Review. Hungarian.

4. O'Leary PC, Feddema PH, Michelangeli VP, Leedman PJ, Chew GT, Knuiman M, Kaye J, Walsh JP. Investigations of thyroid hormones and antibodies based on a community health survey: the Busselton thyroid study. Clin Endocrinol (Oxf). 2006 Jan;64(1):97-104.

5.Köhrle J. Selenium and the thyroid. Curr Opin Endocrinol Diabetes Obes. 2013 Oct;20(5):441-8. doi: 10.1097/01.med. 0000433066. 24541.88. Review. 